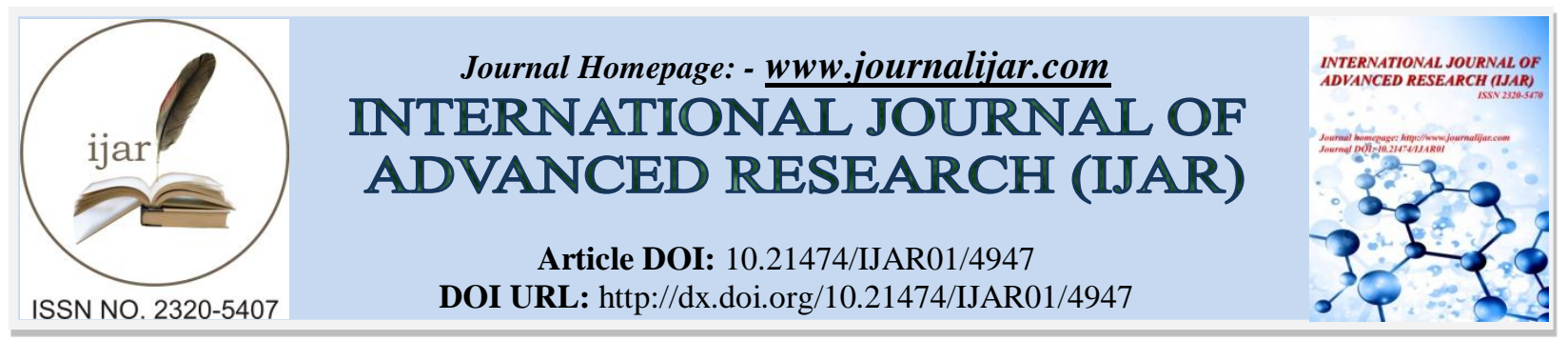

RESEARCH ARTICLE

\title{
PERCEIVED STRESS AND COPING STRATEGIES: A STUDY AMONG SECONDARY SCHOOL STUDENTS.
}

Dr. Gollamudi Subbarao.

Psychologist, National Institute of Nutrition, Hyderabad.

\section{Manuscript Info}

Manuscript History

Received: 24 May 2017

Final Accepted: 26 June 2017

Published: July 2017

Key words:-

Perceived Stress, Coping Strategies and Secondary School Students

\section{Abstract}

The purpose of this study was to examine the relationship between perceived stress and coping strategies of secondary school students. Random sample of 198 government secondary school students were selected for the study. Psychometrically sound instruments to measure perceived stress scale developed by Cohen, Kamarck \& Mermelstein (1983) and Coping strategies scale developed by Srivastava (2001). A correlational research design was used in the study. Results revealed that there is a positive and significant relationship between perceived stress and coping strategies of secondary school students. The study found perceived stress to be having a significant predictor and correlate of coping strategies of secondary school students. The results of the present study suggest that higher the level of perceived stress, the better the level of coping strategies.

Copy Right, IJAR, 2017,. All rights reserved.

\section{Introduction:-}

Education plays very vital role in realizing the hopes and aspirations of the society. In educational process, the student occupies a very important place. A student is the medium through which objectives and plan can be actualized. For this student must have sound mental and physical health. But the rapid development of technology, rich information system, explosion of knowledge has brought a corresponding change in the life and work of people. India in twenty first century is quite different from India of 1947 in terms of social, economic, political and moral values. India has reached at the threshold of space and made a mark information age due to industrialization and electronic revolution. The new diseases which are hitting the newspapers now days are the stress. Thus the modern world which is said to be the world of achievement is also world of stress. One can find stress everywhere, whether it is within in family, business organization, enterprise or any other social and economic activity. Right from the time of birth till the last breath down, an individual is exposed to various stressful situations.

Thus it is not surprising that in their issue has been rising with advancement of present century, which has been called 'Age of anxiety, conflict and stress' In the age of modernization, urbanization and globalization, tension, anxiety, stress and neurosis have became synonyms with the life today. Nowadays most of the work is done by machines. Thus leaving human being with different diseases, consequently the human being do not have sound mind. Usually, people feel spanking new after having slept for seven hours, but people grumble for not having a sound sleep. It reflects that there is something which disturbs their sleep and this only happen if a person does not have sound mind and physical health. To keep one physical and mental health, people join club or become the members of different recreational classes. 
People do use their own exquisite techniques like yoga, meditation, morning walk etc. But these may not be very effective, if one is under a great stress. So stress is a common phenomenon in everyday life. Our educational institutions are also full of stressors of various kinds. The students feel various kinds of stress from the society. There exist stress between student and teachers, stress between teachers associations and head of educational institutions, stress between individuals and family life etc. In reality, stress is invasive in all human experience in our educational institutions.

\section{Review Of Literature:-}

There are numerous tests of coping strategy that mediated the relations between perceived stress and other related variables (e.g. stressors, self-esteem and general health). The distress has shown that coping strategy partially or fully settles the effect of perceived stress on the general health of students (Uchino, 2004).

Blonna (2005) found that a stressful circumstance can be reduced considerably if an individual knows how to cope with it. In addition, Cheng and Cheung (2005) explained that individuals who face stressful circumstances need to have constructive coping strategy. Often it is wise to choose strategies that work in a particular context; such as exercise regularly, seek social support, practice relaxation and so on. Cheng and Cheung further explained that a person who has experienced a cluster of stressful life event would be able to cope successfully with life if he/she is able to modify coping strategy to match the demands of the situation. An effective coping strategy can determine one's outcomes in facing and handling a stressful situation and influence the level of general health state (Uchino, 2004).

\section{Methodology:-}

\section{Research Design:-}

The present research study is a quantitative research study which is based on descriptive research perspective. This research study is a non experimental research study and used a survey research design framework, in which psychometrically sound instruments-questionnaires were used to collect data from the sampled students from different government secondary schools of Telangana State

\section{Sample:-}

Sample consisted of secondary school students $(\mathrm{N}=198)$ between the ages range is 13 to 15 years; Random sampling method was used for the sample selection. Sample selected from Government secondary schools located in Nalgonda District of Telangana State. Data were collected from secondary school students with the permission of concerned authorities. These schools were randomly selected.

\section{Measures:- \\ Description of the Research Instruments:- Perceived Stress Scale:-}

Perceived stress can be viewed as an outcome variable measuring the experienced level of stress as a function of coping processes and personality factors. Perceived stress among the students was assessed using the perceived stress scale (PSS-14) developed by Cohen, Kamarck \& Mermelstein (1983). Group mean scores were used for comparisons and greater scores indicated higher perceived stress. Briefly, PSS is a global scale and identifies the factors influencing or influenced by stress appraisal. It is a 14 -item scale which measures the degree to which situations in one's life is appraised as stressful during the past month. There are seven negative and seven positive questions for which the subjects were required to choose from a scale of 5 alternatives 'never' 'almost never' 'sometimes' 'fairly often' 'very often' relating to their feeling of being stressed on a 0-4 scale. The 7 positive items were reverse scored and added up to the 7 negative items to get the total score.

\section{Perceived Stress Scale Scoring:-}

To assess the degree to which people perceive their lives as stressful. High levels of stress are associated with poor self-reported health, depression, the perceived stress there are seven negative and seven positive questions for which the subjects were required to choose from a scale of 5 alternatives 'never' 'almost never' 'sometimes' 'fairly often' 'very often' relating to their feeling of being stressed on a 0-4 scale. The 7 positive items were reverse scored and added up to the 7 negative items to get the total score. 


\section{Coping Strategies Scale:-}

Coping strategies scale used in the present study has been developed by Srivastava (2001). The responses to the items in this scale is based on a five point scale ranging from (0) Never (1) Rarely, (2) Sometimes, (3) Most of the times to (4) Almost Always. The meaning and definitions of the five major categories of coping strategies is given below.

The present study measure of coping strategies comprises 50 items, describing varieties of coping behaviour underlying following coping strategies based on the combinations of 'Operation' and 'Orientation' of the Coping Behaviour: 1. Active / Approach Coping: Behavioural-Approach Coping Strategies, Cognitive-Approach Coping Strategies, Cognitive-Behavioural-Approach Coping Strategies, 2. Avoidance Coping (Emotion-Focused Coping) Behavioural-Avoidance Coping Strategies and Cognitive-Avoidance Coping Strategies.

\section{Results and Discussion:-}

To examine the relationship between perceived stress and coping strategies, the product moment correlation coefficient was computed between perceived stress and coping strategies scores. The results obtained are presented in table 1.

Table 1:- Means Standard deviation and Correlation Coefficient between perceived Stress and total coping strategies of secondary school students.

\begin{tabular}{|l|l|l|l|}
\hline Variables & Mean & SD & Correlation Coefficient \\
\hline Perceived Stress & 33.21 & 12.992 & $0.705^{* *}$ \\
\cline { 1 - 3 } Coping Strategies & 126.36 & 28.5503 & \\
\hline
\end{tabular}

$* * \mathbf{P}<\mathbf{0 . 0 1}$

From table 1 it can be observed that the correlation coefficients computed between the perceived stress and coping strategies is found to be significant $(\mathrm{p}<0.01)$. The results indicate that a positive and significant relationship between perceived stress and coping strategy $(\mathrm{r}=.705, \mathrm{p}<.01)$. This implies that higher the level of perceived stress, the better the level of coping strategy. The present study is in streak earlier studies discussed in the literature review of the paper Cai-Lian Tam \& Teck-Heang lee (2013).

\section{Conclusion:-}

Stress is seen as a modern society's illness. It causes both psychological and physical disorder (French et al., 1982). Some of the physical disorder, among others, includes craving for food, lack of appetite, constipation, diarrhoea, gastritis, indigestion, heartburn, insomnia and headaches. On the other hand, physical disorder may cause problems such as a lack of interest in life, constant or recurrent fear of disease and a feeling of being bad or of self-hatred. Critical ailments and afflictions such as hypertension, heart attack, skin disorders and tuberculosis are found in more serious cases (Arnold et al., 2005). In view of the detrimental effects of stress, a research study to understand the nature and sources of stress is very much needed as it helps to devise effective remedies to reduce stress. This study aims to explore the interrelationships of perceived stress, coping strategy. Research paper revealed that there was a significant positive relationship between perceived stresses and coping strategies of secondary school students Thus, the hypothesis was accepted. This implies that higher the level of perceived stress, the better the level of coping strategy. In general the findings of with the present study are in line previous studies discussed in the literature review of the paper such as Morgan (1997), Walton (2002), Beck (1995), Blonna (2005), and Litmand and Lunsford (2009). The results of this study show that secondary school students, regardless of gender, ethnicity and nationality may encounter numerous stressors in their student life. The perceived stress may vary from meeting deadlines to reaching expectations and coping in a new environment.

The study proved that perceived stress, coping strategies are interrelated. Hence, it is essential to raise awareness among parents, educators and people from all walks of life to provide constructive strategies to ensure that the needs of these students are met. In addition, as coping capability are important in moderating stress every possible action should be taken to enhance the coping strategy of students. To provide time management seminars, counselling services and healthy co-curricular activities can well be implemented in the schools to help students reduce their stress. 


\section{References:-}

1. Arnold, J., Silverster, J., Patterson, F., Robertson, I., Cooper, C., \& Burnes, B. (2005), "Work Psychology (4th ed.)", Prentice Hall.

2. Beck, C. T. (1995), "Burnout in undergraduate nursing students", Nurse Educator, Vol. 20, No. 4, pp. 19-23.

3. Blonna, R. (2005). "Coping with stress in a changing world (3rd ed.)", New York: McGraw-Hill.

4. Bhatnagar, D \& Bose, K. (1985). Organizational role stress and branch manager. The Asian Journal of Psychology of education (2009) 42 (3-4), 25, Tiwari Kothi, Belaganj, Agra.

5. Cai-Lian Tam \& Teck-Heang lee (2013). Perceived stress, coping strategy and General health: a study on accounting Students in Malaysia. International Refereed Research Journal, vol 4 (1), pp 88-95.

6. Cohen. S., Kamarck, T., \& Mermelstein, R. (1983). A Global Measure of Perceived Stress. Journal of Health Social Behaviour, 24, 385-96.

7. French, J. R. P., Caplan, R. D., \& Harrison, R. V. (1982), "The mechanisms of job stress and strain", Chichester, England: Wiley.

8. Litman, J. A., \& Lunsford, G. D. (2009), "Frequency of use and impact of coping strategies assessed by the COPE inventory and their relationships to post-event health and well-being", Journal of Health Psychology, Vol. 14, pp. 982-991.

9. Srivastava, A.K. (2001). Manual of coping strategies scale, Banaras Hindu University. Varanasi: Rupa Psychological Centre. 